CAHAYAtéch
Jurnal Teknik Informatika, Sistem Informasi, dan Ilmu Komputer, 8 (2) (2019) $2580-2399$
Website: ojs.cahayasurya.ac.id/index.php/CT
Research paper, Short communication, Review, Technical paper

\title{
Balanced Scorecard untuk Menganalisis Penerapan Knowledge Management System di Sekolah Tinggi Teknologi Cahaya Surya Kediri
}

\author{
Maikel Bolung', Heri Abijono², Elkana Lewi Santoso ${ }^{3}$ \\ ${ }^{1}$ Sekolah Tinggi Manajemen Informatika dan Komputer PARNA RAYA Manado \\ ${ }^{2,3}$ Sekolah Tinggi Teknologi Cahaya Surya Kediri \\ E-mail: ${ }^{1}$ bolungmaikel@gmail.com, 2ahabijono@gmail.com, ${ }^{3}$ elkanaliu@gmail.com
}

\begin{abstract}
Abstrak
Penerapan knowledge management di perguruan tinggi telah menjadi kebutuhan mendasar sekarang ini. Kemampuan dalam mengelola pengetahuan yang ada merupakan kekuatan yang dibutuhkan perguruan tinggi untuk tetap bertahan dan semakin maju. Knowledge management merupakan usaha untuk meningkatkan dan mengelola pengetahuan menjadi lebih berkualitas bagi perguruan tinggi. Penelitian ini menganalisis penerapan Knowledge Management System (KMS) di Sekolah Tinggi Teknologi (STT) Cahaya Surya Kediri melalui situsnya www.cahayasurya.ac.id menggunakan metode Balanced Scorecard untuk mengukur penerapan KMS berbasis website di STT Cahaya Surya. Hasil dari penelitian ini dapat menunjukkan hal-hal mana yang menjadi kekurangan dan dapat diusulkan perbaikan sistem website itu, sehingga sistem website STT Cahaya Surya dapat benar-benar menjadi siatu situs yang menerapkan KMS dan bermanfaat bagi para penggunanya.
\end{abstract}

Kata Kunci- knowledge, management, sistem, menerapkan, bermanfaat

\section{Pendahuluan}

\subsection{Latar Belakang Masalah}

Penerapan knowledge management di sebuah perguruan tinggi sudah menjadi kebutuhan mendasar untuk saat ini. Kemampuan mengelola pengetahuan menjadi kekuatan yang dibutuhkan perguruan tinggi agar tetap dipertahankan jika institusi ingin semakin maju di dalam persaingan. Knowledge management merupakan usaha untuk meningkatkan dan mengelola pengetahuan menjadi lebih berkualitas bagi perguruan tinggi.

Penerapan knowledge management dengan sistem berbasis web merupakan suatu solusi untuk menerapkan sistem pengelolaan pengetahuan. Kurangnya pemahaman dalam menerapkan dan memaksimalkan Knowledge management System (KMS) yang baik di Sekolah Tinggi Teknologi Cahaya Surya Kediri (STT CSK) menyebabkan terhambatnya transfer knowledge, kualitas pendidikan yang tidak terkontrol dan bahkan menurun, sehingga tidak konsisten menghasilkan pengetahuan baru dan dapat menurunkan minat calon peserta didik untuk menjadi mahasiswa. Pengelolan pengetahuan pada akhirnya dapat menjadi dukungan yang handal bagi institusi dalam meningkatkan daya saing (Yuliazmi, 2005).

Kebutuhan yang harus dijawab STT CSK sebagai lembaga pendidikan tinggi adalah agar dapat miningkatkan kualitas organisasi, proses pembelajaran dan aktivitas staf akademik 
yang baik dalam melakukan inovasi, komunikasi, berbagi pengetahuan dan penguasaan teknologi informasi. Hal ini telah mendorong peneliti untuk menganalisis penerapan KMS dalam menjawab kebutuhan di atas, sehingga dapat memberi masukan dan rekomendasi dalam memperbaiki kekurangan serta bisa meningkatkan sumber daya, penggunaan kembali pengetahuan yang sudah ada serta mempercepat proses pengembangan dan penciptaan pengetahuan baru. Di dalam penelitian Davenport and Prusak (1988) disebutkan bahwa pengetahuan adalah salah satu sumber daya strategic yang sangat penting dalam lingkungan yang cenderung cepat berubah dewasa ini.

Tidak adanya kesadaran akan pentingnya melakukan pengukuran dan penerapan KMS dapat menghambat inovasi, komunikasi, penguasaan teknologi, mengelola dan memanfaatkan knowledge yang ada juga berbagi pengetahuan. Berdasarkan uraian yang sudah ditulis di atas, rumusan masalah dalam penelitian ini adalah "apakah STT CSK sebagai institusi pendidikan tinggi telah memahami, mengelola, mengembangkan dan menerapkan Knowledge Management System (KMS) yang dimilikinya, serta menciptakan keunggulan daya saing serta mewujudkan visi, misi dan tujuan institusi?

Tujuan yang ingin dicapai melalui penelitian ini adalah: 1) Mengukur penerapan KMS pada pada website STT CSK dengan menggunakan metode Balanced Scorecard, dan 2) Memberikan usulan dan rekomendasi pengembangan KMS berbasis website pada STT CSK agar KMS benar-benar diterapkan di dalamnya, sehingga situs web http://www.cahayasurya.ac.id bukan hanya sekedar menjadi media informasi searah, namun dapat pula menjadi sarana knowledge collecting, sharing sampai knowledge storage.

\section{Landasan Teori}

\subsection{Penelitian bidang Knowledge Management}

Penelitian pada bidang Knowledge Management telah dilakukan pada beberapa perguaruan tinggi dan perusahaan antara lain oleh Suhitarini Soemarto Putri dan Togar Harapan Pangaribuan (2009) dengan tujuan membangun budaya Knowledge Sharing antar pegawai menggunakan MOODLE sebagai media pembelajaran secara individu dan memahami budaya berbagi pengetahuan. Pada penelitian Winda Kurnia Sari dan Ken Ditha Tania (2014) menggunakan metode 10-step knowledge management roadmap bertujuan membuat KMS berbasis web di bagian Teknisi dan Jaringan dari Fakultas Ilmu Komputer Unversitas Sriwijaya berhasil memfasilitasi terjadinya seluruh proses pengelolaan pengetahuan SECI, serta menjamin keberlangsungan pengelolaan pengetahuan dan kelayakan pengetahuan yang dipublikasikan.

Dalam penelitian dari Steven Ray Sentinuwo (2010) didapatkan bahwa sumber daya intelektual dan informasi yang dimiliki setiap orang dalam sebuah perguruan tinggi merupakan asset yang bernilai dan harus dimanfaatkan secara optimal untuk meningkatkan kualitas dan nilai organisasi serta meningkatkan produktifitas dan daya saing. Penelitian ini berhasil menentukan model penerapan KMS yang cocok untuk lingkungan perguruan tinggi dengan mengintegrasikan konsep Balanced Scorecard (BSC). Dalam penelitian yang dilakukan Santoro dkk (2017) tujuan utamanya adalah untuk meneliti hubungan antara KMS, open innovation, knowledge management capacity dan innovation capacity, serta bagaimana hubungan ini mempengaruhi kapasitas inovasi perusahan. Pada saat ini manajemen pengetahuan dipengaruhi secara signifikan oleh kemajuan teknologi dan tindakan kolaboratif antara pelaku ekonomi sehingga dalam konteks ini, the Internet of Things menawarkan kesempatan baru bagi bisnis untuk memperbaiki praktik pengelolaan pengetahuan dan untuk meningkatkan arus pengetahuan melalui ICT yang maju.

Penelitian yang dilakukan oleh Semlinda Juszandri Bulan dan Indra Sensuse (2012) menyatakan bahwa knowledge sharing adalah sangat penting dalam suatu organisasi, salah satu dampaknya yaitu untuk mengembangkan dayaguna dan prestasi perusahan. Dalam sector pendidikan, efektifitas knowledge sharing diantara staff akademik dapat meningkatkan kualitas perguruan tinggi tersebut. Penelitian ini bermaksud untuk mengusulkan sebuah model 
knowledge sharing diantara staff akademik. Penelitian dengan obyek perguruan tinggi juga dilakukan oleh Agus Mulyanto (2008) yang bertujuan untuk mengimplementasikan knowledge management melalui knowledge sharing di institusi Perguruan Tinggi.

Pengelolaan pengetahuan dalam suatu Perguruan Tinggi adalah mutlak diperlukan. Masalah yang sering muncul dalam pengelolaan pengetahuan di Perguruan Tinggi adalah knowledge sharing yang belum menjadi budaya dan kemauan. Knowledge sharing selain untuk kepentingan institusi adalah juga baik untuk diterapkan secara individu. Pada penelitian yang dilakukan oleh Ridho Nur Imansyah (2010) yang bertujuan untuk mengukur performansi knowledge management yang di implementasi dalam suatu perusahaan dan pengaruh knowledge management terhadap meningkatkan target perusahan menggunakan beberapa model pendekatan seperti Balanced Scorecard untuk melakukan pengukuran performansi perusahan, juga pengukuran indikator kinerja knowledge management yang membagi fokus pada 3 area yaitu People, Process, IT (Technology) untuk mendapatkan gambaran sejauh mana tingkat kapabilitas dan performansi dari knowledge management yang berjalan.

\subsection{Pengertian Knowledge Management}

Pembahasan mengenai knowledge management merupakan suatu rangkaian kegiatan mengidentifikasi, menciptakan, mengelola, mengukur, menjelaskan, dan mendistribusikan pengetahuan untuk diketahui, dipelajari, dan digunakan dalam suatu organisasi. Knowledge management adalah suatu disiplin ilmu yang mempromosikan suatu pendekatan terintegrasi terhadap pengidentifikasian, pengelolaan, dan pendistribusian semua asset informasi yang dimiliki suatu organisasi (Koina dalam Siregar, 2005). Knowledge management meliputi strategi manajemen, metode, dan teknologi untuk melindungi modal intelektual perusahaan dan langkah-langkah pengerjaan untuk mencapai hasil optimal dalam unjuk kerja dan daya saing. Aset informasi ini bisa berupa database, dokumen, kebijakan, prosedur, dan keahlian serta pengalaman yang dimiliki oleh karyawan.

Knowledge management termasuk membangun, mengimplementasikan, dan memelihara infrastruktur teknis dan organisasi untuk memungkinkan saling berbagi knowledge serta memilih vendor dan teknologi tertentu yang dapat mendukungnya. Knowledge management merupakan sebuah proses yang di dalamnya berisi proses mendapatkan (discovering), proses menangkap knowledge (capturing), proses berbagi knowledge (sharing), dan proses menerapkan knowledge (applying). Empat knowledge management process ini didukung oleh Knowledge management System (Bacerra, 2003). Knowledge merupakan kemampuan seseorang/individu dalam menghubungkan dan mengaitkan setiap informasi yang dimiliki olehnya dengan konsep-konsep lain yang relevan dengan area tertentu untuk digunakan dalam proses pengambilan keputusan.

Berbeda dengan data informasi, sebuah knowledge erat kaitannya dengan konteks yang menentukan relevansi sebuah informasi terhadap situasi atau kondisi tertentu (Schneider, 2009)..Dalam buku yang ditulis oleh Becerra-Fernandez, disebutkan bahwa knowledge tidak jauh dari data dan informasi walaupun ketiganya dapat dipertukarkan dalam penggunaannya. Knowledge merujuk kepada informasi yang mengandung actions dan decisions. Knowledge memiliki keterkaitan antara data dan informasi dimana knowledge didefinisikan sebagai data dan informasi yang digabung dengan kemampuan, intuisi, pengalaman, gagasan, motivasi dari sumber yang kompeten. Knowledge merupakan level tertinggi, sedangkan informasi pada level menengah, dan data pada level rendah. Knowledge dapat merujuk pada suatu informasi yang memiliki arah, aksi, dan membuat keputusan, dimana aksi dan keputusan menjadi poin penting dalam sebuah knowledge yang dirujuk dari sebuah informasi.

Nonaka dan Takeuchi mengemukakan bahwa alasan fundamental mengapa perusahaan Jepang sukses, kerena ketrampilan dan pengalaman mereka terdapat pada penciptaan knowledge organisasi. Penciptaan knowledge dicapai melalui pengenalan hubungan sinergik antara tacit knowledge dan explicit knowledge. Pada tahun 1991 dan 1995, Nonaka et.al. membedakan antara tacit knowledge dan explicit knowledge, dan membagi model konversi knowledge menjadi 4 cara seperti yang ditunjukkan melalui Gambar 2.1. 


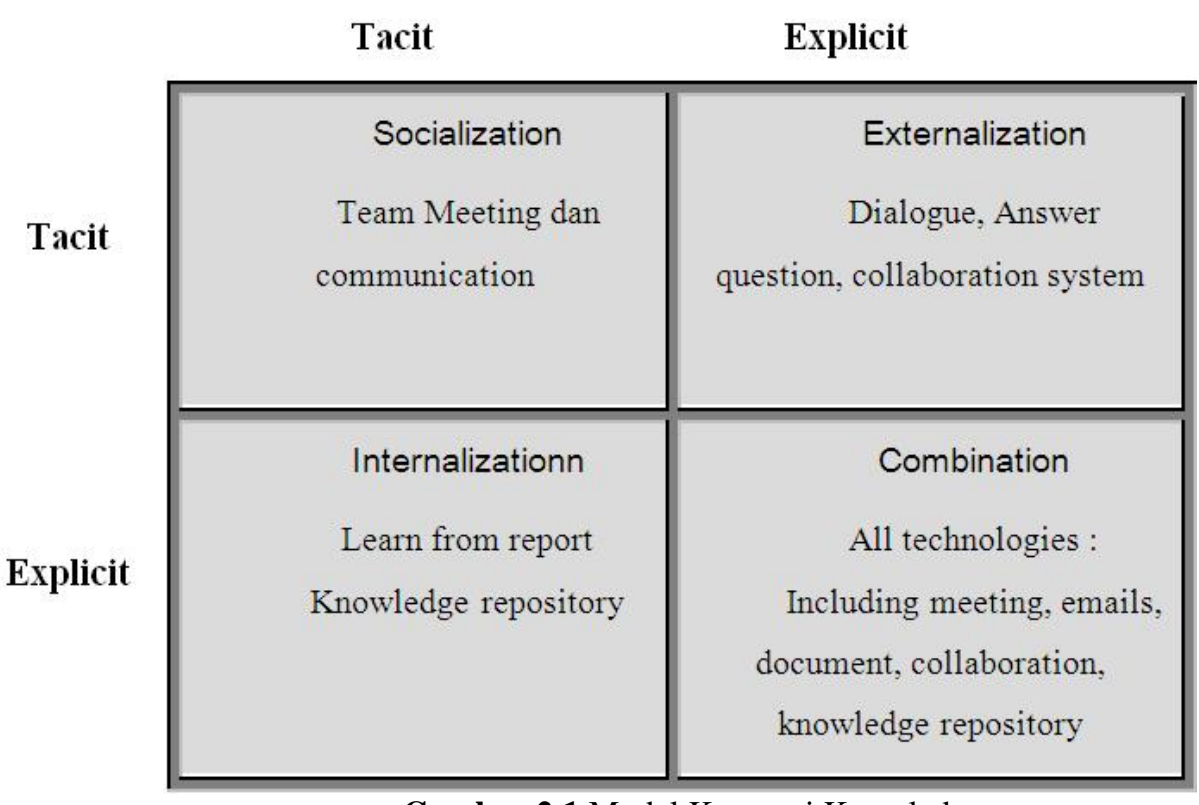

Gambar 2.1 Model Konversi Knowledge

Penjelasan peneliti mengenai model konversi knowledge di Gambar 1 adalah sebagai berikut: 1) Tacit knowledge ke explicit knowledge disebut proses Externalization, 2) Tacit knowledge ke tacit knowledge disebut proses Socialization, 3) Explicit knowledge ke explicit knowledge disebut proses Combination, dan 4) Explicit knowledge ke tacit knowledge; disebut proses Interlization.

Dalam aplikasinya, tacit knowledge dan explicit knowledge memiliki penanganan yang berbeda karena keduanya jelas berbeda. Sebagai contoh, pada penanganan suatu permasalahan jaringan, seorang network engineer menggunakan intuisinya dalam menganalisis masalah yang ada. Setiap individu pasti memiliki intuisi yang berbeda dan terkadang intuisi tersebut yang menyebabkan penyelesaian masalah lebih cepat dikerjakan.Namun, agar tacit knowledge dapat ditangkap menjadi data yang kemudian dapat dipadukan menjadi sebuah informasi, dapat dilakukan konversi dari tacit knowledge ke explicit knowledge (Bacerra, 2003).

Bahasan mengenai knowledge management sudah dijabarkan pada penjelasan di atas. Sistem adalah perpaduan dari beberapa bagian suatu aksi yang dikerjakan bersama-sama. Knowledge management system dapat diartikan sebagai kumpulan proses yang mengoordinasi penggunaan informasi, pengetahuan, dan pengalaman yang berjalan dan bekerja bersama-sama.

\subsection{Balanced Scorecard}

Dalam penelitian dari Steven Ray Sentinuwo (2010) didapatkan bahwa sumber daya intelektual dan informasi yang dimiliki setiap orang dalam sebuah perguruan tinggi merupakan asset yang bernilai dan harus dimanfaatkan secara optimal untuk meningkatkan kualitas dan nilai organisasi serta meningkatkan produktifitas dan daya saing. Penelitian ini berhasil menentukan model penerapan KMS yang cocok untuk lingkungan perguruan tinggi dengan mengintegrasikan konsep Balanced Scorecard (BSC).

\subsection{Situs Website STT Cahaya Surya Kediri}

Sebagai perguruan tinggi yang bergerak di bidang teknologi dan informasi, STT CSK situs web (Gambar 2) yang menyajikan informasi seputar kegiatan akademik serta informasi teknologi lainnya. Penggunaan situs web masih sangat terbatas dalam penyajian informasi berita dan perlu di-update. Situs web dapat lebih dimaksimalkan sebagai media komunikasi antara mahasiswa dan pihak akademik, media pembelajaran, dan sarana sharing knowledge antara dosen dan mahasiswa/i, juga sesama mahasiswa/i. 


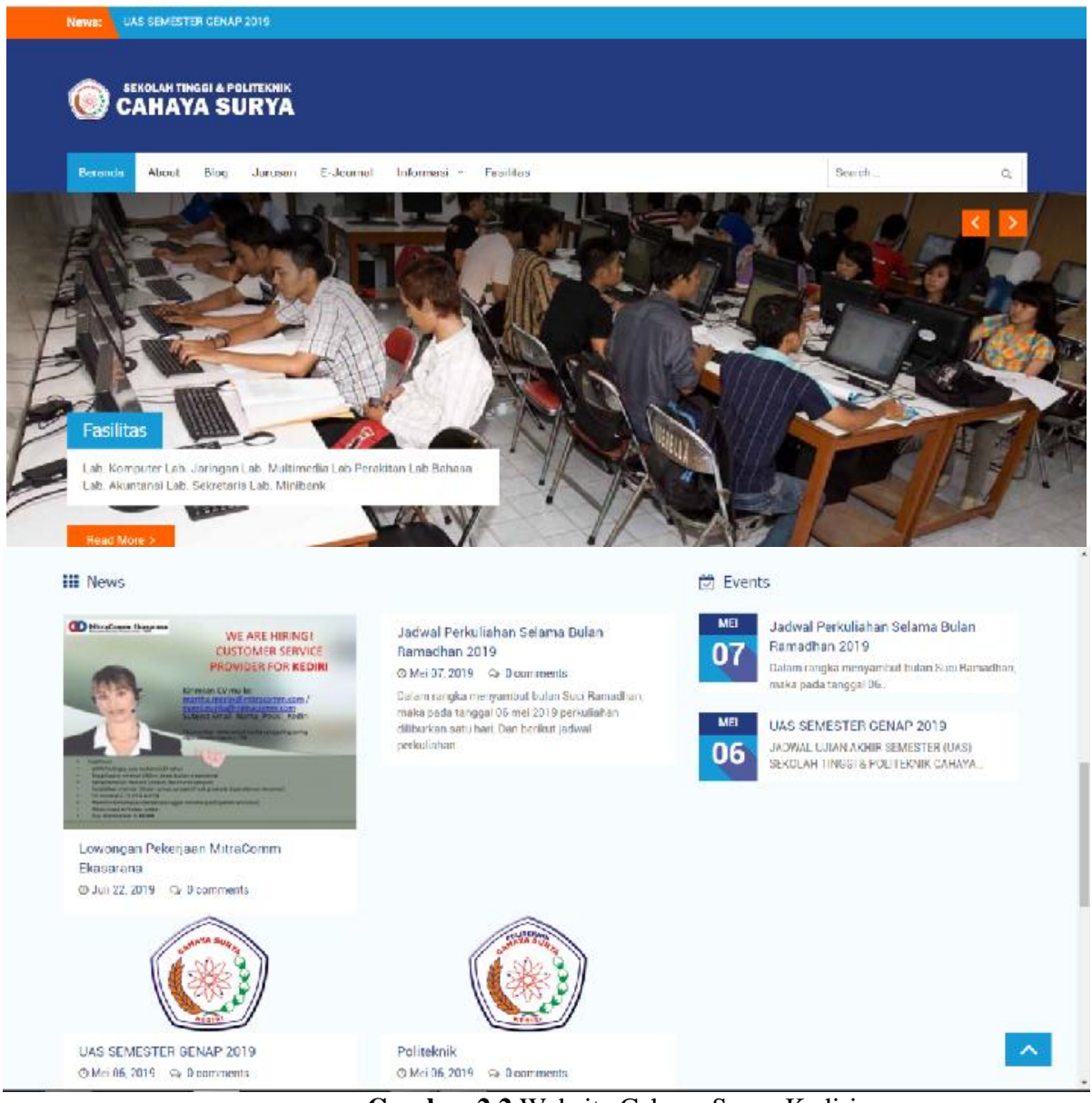

Gambar 2.2 Website Cahaya Surya Kediri

\section{Perancangan Sistem}

Alur penelitian yang akan digunakan untuk mengukur penerapan KMS pada STMIK Parna Raya Manado dapat disusun menjadi suatu skema seperti pada Gambar 3.1.

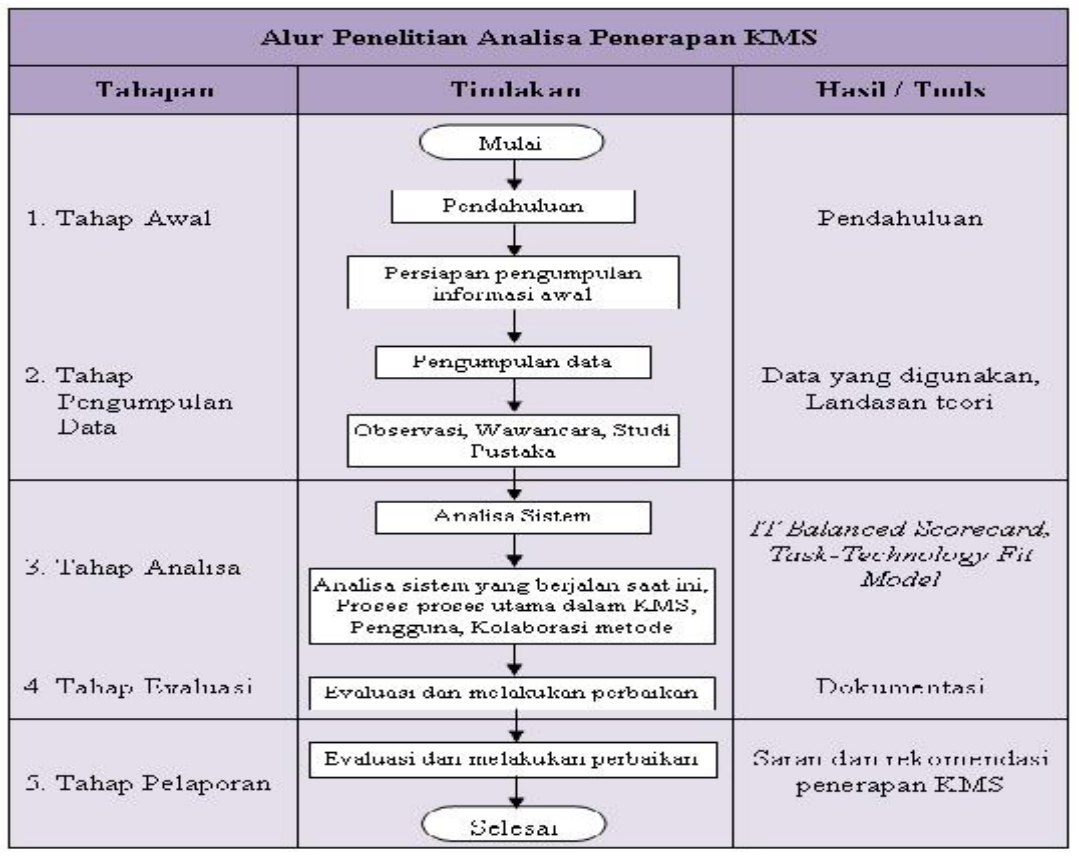

Gambar 3.1 Alur Penelitian pada STT Cahaya Surya Kediri 
Skema dari alur penelitian pada gambar 3.1 dapat dijelaskan sebagai berikut:

1. Di tahap awal penelitian, peneliti mengumpulkan informasi dari secara lisan dari para pengguna sistem website STT Cahaya Surya Kediri untuk mengetahui keunggulan dan kelemahan yang dapat ditemukan terdapat pada sistem website tersebut.

2. Pada tahap pengumpulan data, peneliti melakukan studi pustaka untuk mempelajari teori formal mengenai metode Balance Scorecard dan mengumpulkan informasi mengenai penelitianpenelitian yang lain yang telah menerapkan metode itu. Untuk tahap pengumpulan data dari pengguna sistem website, peneliti melakukan pengumpulan data dengan observasi dan wawancara kepada para mahasiswa STT Cahaya Surya Kediri.

3. Di tahap analisis sistem, peneliti menganalisis proses-proses yang telah ada maupun yang belum ada pada sistem website STT Cahaya Surya Kediri, baik itu pada subsistem perpustakaan elektronik maupun pada subsistem $e$-Learning.

4. Pada tahap evaluasi sistem, peneliti melakukan evaluasi terhadap kelemahan yang ditemukan pada tahap analisis, dan membuat suatu usulan untuk fitur-fitur yang perlu ditambahkan serta memerinci keunggulan / potensi manfaat dari fitur-fitur yang akan ditambahkan itu.

5. Pada tahap pelaporan, peneliti menyampaikan saran ataupun bahan rekomendasi untuk perbaikan sistem kepada pimpinan STT Cahaya Surya Kediri.

\section{Implementasi Dan Pembahasan}

\subsection{Gambaran Umum Obyek Penelitian}

Visi STT Cahaya Surya Kediri adalah "Menjadi program studi S1 Teknik Informatika yang menghasilkan Sarjana Komputer yang profesional, kompetitif dan unggul dalam bidang komputer dan IT Enterpreuneur di Kediri tahun 2025." Misi program studi S1 Teknik Informatika STT Cahaya Surya terdiri dari:

1. Menyelenggarakan pendidikan (pengajaran, penelitian, pengembangan ilmu pengetahuan serta pengabdian masyarakat) yang bermuara pada mencerdaskan sumber daya manusia berbasis komputer dan informatika.

2. Melaksanakan kegiatan penelitian dan pengabdian kepada masyarakat dalam bidang teknologi informasi dan bidang lain yang relevan dengan kebutuhan masyarakat.

3. Menjalin kerjasama saling menguntungkan dengan lembaga-lembaga terkait untuk penerapan dan pengembangan ilmu Teknik Informatika.

Tujuan program studi S1 Teknik Informatika Cahaya Surya adalah:

1. Menghasilkan lulusan yang memiliki kompetensi keahlian dan mampu mengaplikasikan ilmu Teknik Informatika di dunia industri secara produktif dan aplikatif.

2. Menghasilkan karya penelitian dan kegiatan pengabdian kepada masyarakat yang aplikatif dan bermanfaat bagi masyarakat dibidang Teknik Informatika.

3. Mampu mengembangkan Sumber Daya untuk pengembangan Teknologi di Era Revolusi Industri 4.0.

4. Mampu membaca peluang dan mengelola pemanfaatan teknologi menjadi IT Enterpreneur yang inovatif.

5. Mampu Mengoperasikan perangkat teknologi informasi secara handal untuk peningkatan dan pengembangan produktifitas kerja secara mandiri.

\subsection{Analisis dengan Balanced Scorecard}

Tahapan-tahapan analisis dengan metode BSC dapat diperinci dari beberapa perspektif sebagai berikut:

1. Perspektif Riset dan Pengembangan

a. Prosedur dan administratif yang berhubungan dengan kegiatan riset serta pengalaman terbaik, termasuk: a) Data tentang ketertarikan dan peluang hasil penelitian yang dapat dikomersilkan, b) Data-data hasil riset dan informasi bantuan pemerintah untuk pengembangan, c) Kesempatan mendapatkan biaya riset, d) Koleksi proposal yang pernah ada, e) Kebijakan dan prosedur pembuatan proposal, f) Pengumuman, prosedur 
penilaian, dan kebijakan serta prosedur negosiasi, g) Perjanjian kontrak dan kebijakan serta prosedur pengolahan dana bantuan, h) Format laporan teknis dan keuangan serta kebijakan dan prosedur, i) Gambaran tentang layanan internal, sumber daya dan karyawan (dosen dan pegawai).

Potensi Manfaat: a) Memberikan peluang untuk komersialisasi hasil-hasil riset, b) Menciptakan peluang untuk dapat melakukan riset intra pada disiplin ilmu yang berbeda, c) Memanfaatkan hasil-hasil riset yang ada dan mendorong munculnya proposal riset, d) Membantu dalam menentukan domain atau tema penelitian yang akan dilakukan, e) Mengurangi biaya koneksi Internet untuk kegiatan riset.

b. Aplikasi penyimpanan data revisi kurikulum, termasuk juga hasil penelitian yang pernah dilakukan, pengalaman terbaik, dan hasil-hasil pelatihan.

Potensi manfaat: Meningkatkan kualitas kurikulum dan program-program melalui identifikasi dan mempelajari pengalaman dan hasil yang telah ada.

c. Aplikasi website yang sedang diteliti ini dapat berperan sebagai: a) Pusat informasi dari setiap program studi, termasuk didalamnya materi / informasi terbaru, data publikasi, dan data-data penelitian. b) Penyimpanan teknik-teknik pengajaran dan penilaian, termasuk pengalaman terbaik untuk dampak maupun manfaat dan peluang dalam mengembangkan program studi. c) Penyimpanan hasil evaluasi mahasiswa yang terbaru dan telah dianalisa sebagai bahan pembelajaran dan pengalaman terbaik bagi program studi yang ada.

Potensi Manfaat: a) Meningkatkan fleksibilitas dan respon berdasarkan hal-hal yang dapat dipelajari dari pengalaman pihak lain dan hasil evaluasi mahasiswa. b) Meningkatkan kualitas dosen khususnya dalam hal pengajaran dan penilaian. Sehingga dari peningkatan kualitas ini akan berdampak pada percepatan masa studi ataupun masa studi yang tepat waktu.

2. Perspektif Konsumen

a. Website yang sedang diteliti pada penelitian ini memiliki layanan-layanan: a) Informasi mengenai syarat dan prosedur yang berhubungan dengan pendaftaran mahasiswa baru. b) Informasi mengenai koleksi perpustakaan. c) Informasi mengenai koleksi jurnal/tulisan ilmiah. Potensi manfaat: meningkatkan kepuasan mahasiswa sebagai komponen user.

b. Website ini dapat menjadi sebuah layanan yang menguntungkan bagi mahasiswa dan juga bagi institusi sebagai informasi yang berharga. Di dalamnya termasuk juga informasi data alumni serta dihubungkan dengan aktivitas pengembangan kurikulum, riset dan karir. Potensi manfaat: Dapat meningkatkan layanan kepada mahasiswa, alumni, dan pihak luar sebagai pengguna tenaga kerja.

3. Perspektif Proses Bisnis Internal

a. Beberapa fitur yang terdapat di dalam website yang sedang diteliti ini meliputi: a) Ruang untuk melakukan tanya-jawab antara pengunjung website dengan admin sistem. b) Informasi mengenai aturan-aturan yang terkait dengan pengisian KRS online, prosedur pendaftaran mahasiswa baru, dan pendaftaran pengunjung website sebagai anggota digital library. c) Informasi mengenai pengalaman dari para alumni. d) Beberapa link yang mengkait ke sistem STBA Cahaya Surya Kediri dan Politeknik Cahaya Surya Kediri. Potensi Manfaat: a) Menyediakan informasi yang lebih baik. b) Meningkatkan fleksibilitas dan kemampuan dalam menghadapi trend ke depan dengan menyediakan garis pedoman untuk menjamin adanya konsistensi. c) Meningkatkan respon dan kemampuan dalam bertukar informasi.

b. Beberapa fungsi yang terdapat pada website yang sedang diteliti ini adalah: a) Pengunjung website dapat melakukan tanya-jawab dengan admin sistem. b) Pengunjung website dapat mengetahui aturan pengisian FRS online, dan dapat melakukan pendaftaran sebagai anggota agar dapat mengakses sistem website digital library maupun sistem website E-journal. c) Dapat mengetahui informasi-informasi dari STBA Cahaya Surya Kediri dan Politeknik Cahaya Surya Kediri. Potensi 
manfaat: a) Meningkatkan fleksibilitas dalam menghadapi trend di masa depan serta membantu dalam pengambilan keputusan yang tepat. b) Dengan adanya informasi internal dan eksternal yang terpusat maka usaha pencarian informasi menjadi lebih mudah.

4. Perspektif Finansial

a. Melalui sistem website ini antarkomunitas dapat saling bertukar informasi yang dapat mendorong usaha perbaikan dan peningkatan kualitas layanan.

Potensi manfaat: a) Meningkatkan fleksibilitas dan kemampuan dalam menghadapi trend ke depan dengan menyediakan garis pedoman untuk menjamin adanya konsistensi. b) Memberikan sarana untuk berbagi pengetahuan. c) Meningkatkan respon dan kemampuan dalam bertukar informasi.

Dalam menganalisis dengan metode Balance Scorecard ini peneliti juga memakai angket kuisioner yang ditujukan kepada 25 responden untuk mengetahui respon mereka terhadap dua hal yang dianalisis. Skor nilai untuk angket ini mencakup batasan nilai-nilai sebagai berikut: STP (sangat tidak puas) memiliki nilai 1, TP (tidak puas) memiliki nilai 2, CP (cukup puas) memiliki nilai 3, P (puas) memiliki nilai 4, dan SP (sangat puas) memiliki nilai 5.

Tabel 1 di bawah ini berisi data hasil penilaian yang disusun oleh peneliti untuk hasil penilaian terhadap mengevaluasi pengaruh penerapan Balanced Scorecard terhadap kepuasan pengguna melalui jawaban angket telah dikembalikan oleh para responden kepada peneliti.

Tabel 4.1. Skor Jawaban Responden tentang Kepuasan Pengguna

\begin{tabular}{|l|l|l|l|l|l|l|l|l|l|}
\hline \multicolumn{10}{|c|}{} \\
\hline 1 & 2 & 3 & 4 & 5 & 6 & 7 & 8 & 9 & 10 \\
\hline 4 & 4 & 4 & 4 & 4 & 4 & 4 & 4 & 4 & 4 \\
\hline 4 & 4 & 4 & 4 & 4 & 4 & 5 & 5 & 3 & 5 \\
\hline 3 & 2 & 3 & 4 & 4 & 4 & 3 & 2 & 4 & 4 \\
\hline 3 & 3 & 4 & 4 & 4 & 4 & 4 & 4 & 4 & 4 \\
\hline 3 & 2 & 4 & 4 & 4 & 4 & 4 & 4 & 4 & 4 \\
\hline 3 & 2 & 2 & 3 & 4 & 4 & 4 & 4 & 4 & 4 \\
\hline 3 & 3 & 3 & 3 & 4 & 4 & 4 & 4 & 4 & 4 \\
\hline 5 & 5 & 3 & 5 & 4 & 4 & 4 & 4 & 4 & 4 \\
\hline 4 & 4 & 4 & 4 & 2 & 3 & 4 & 4 & 4 & 4 \\
\hline 5 & 5 & 2 & 5 & 4 & 4 & 4 & 4 & 4 & 4 \\
\hline 4 & 4 & 4 & 4 & 4 & 3 & 2 & 4 & 4 & 4 \\
\hline 4 & 3 & 4 & 3 & 3 & 4 & 3 & 4 & 3 & 4 \\
\hline 4 & 4 & 3 & 2 & 4 & 3 & 3 & 2 & 2 & 2 \\
\hline 4 & 5 & 4 & 4 & 4 & 4 & 4 & 4 & 4 & 4 \\
\hline 5 & 5 & 2 & 5 & 4 & 4 & 4 & 4 & 4 & 4 \\
\hline 5 & 5 & 3 & 5 & 4 & 4 & 4 & 4 & 4 & 4 \\
\hline 3 & 2 & 2 & 3 & 4 & 4 & 4 & 4 & 3 & 4 \\
\hline 3 & 3 & 4 & 4 & 4 & 4 & 4 & 4 & 4 & 4 \\
\hline 4 & 4 & 4 & 4 & 4 & 4 & 4 & 4 & 4 & 4 \\
\hline 4 & 4 & 4 & 4 & 4 & 3 & 2 & 4 & 4 & 4 \\
\hline 4 & 4 & 4 & 4 & 2 & 3 & 4 & 4 & 4 & 4 \\
\hline 3 & 3 & 3 & 3 & 4 & 4 & 4 & 4 & 4 & 4 \\
\hline 3 & 2 & 4 & 4 & 4 & 4 & 4 & 4 & 4 & 4 \\
\hline 3 & 2 & 3 & 4 & 4 & 4 & 4 & 4 & 3 & 2 \\
\hline 4 & 4 & 4 & 4 & 4 & 4 & 4 & 4 & 4 & 4 \\
\hline
\end{tabular}




\begin{tabular}{|c|c|c|c|c|c|c|c|c|c|}
94 & 88 & 85 & 97 & 95 & 95 & 94 & 97 & 94 & 97 \\
\hline 125 & 125 & 125 & 125 & 125 & 125 & 125 & 125 & 125 & 125 \\
\hline 75.2 & 70.4 & $\mathbf{6 8}$ & 77.6 & 76 & 76 & 75.2 & 77.6 & 75.2 & 77.6 \\
\hline
\end{tabular}

Dari hasil analisis pada Tabel 4.1, nilai terendah sebesar 68 untuk poin kenyamanan yang diberikan oleh sistem di dalam melayani para mahasiswa. Tabel 4.2 di bawah ini berisi data hasil penilaian responden untuk mengevaluasi proses kinerja sistem.

Tabel 4.2. Skor Jawaban Responden tentang Proses Kinerja Sistem

\begin{tabular}{|c|c|c|c|c|c|c|c|c|c|}
\hline \multicolumn{10}{|c|}{ Item Kuisioner } \\
\hline 1 & 2 & 3 & 4 & 5 & 6 & 7 & 8 & 9 & 10 \\
\hline 4 & 4 & 4 & 4 & 4 & 4 & 2 & 4 & 4 & 4 \\
\hline 4 & 4 & 4 & 4 & 4 & 4 & 4 & 5 & 5 & 4 \\
\hline 4 & 4 & 4 & 4 & 4 & 4 & 3 & 4 & 4 & 4 \\
\hline 4 & 4 & 4 & 4 & 4 & 4 & 4 & 2 & 4 & 4 \\
\hline 2 & 4 & 4 & 4 & 4 & 4 & 4 & 4 & 4 & 4 \\
\hline 4 & 5 & 5 & 4 & 4 & 4 & 4 & 4 & 4 & 4 \\
\hline 3 & 4 & 4 & 4 & 4 & 4 & 4 & 4 & 4 & 4 \\
\hline 4 & 3 & 4 & 4 & 4 & 4 & 4 & 4 & 4 & 4 \\
\hline 4 & 2 & 4 & 3 & 4 & 4 & 4 & 4 & 4 & 4 \\
\hline 3 & 4 & 4 & 4 & 4 & 4 & 4 & 4 & 4 & 4 \\
\hline 2 & 4 & 4 & 3 & 4 & 4 & 4 & 4 & 4 & 4 \\
\hline 4 & 4 & 4 & 4 & 4 & 4 & 4 & 4 & 4 & 4 \\
\hline 3 & 4 & 4 & 4 & 2 & 4 & 4 & 4 & 4 & 4 \\
\hline 4 & 4 & 4 & 4 & 4 & 4 & 4 & 3 & 4 & 4 \\
\hline 2 & 4 & 4 & 4 & 4 & 4 & 3 & 4 & 4 & 4 \\
\hline 4 & 4 & 4 & 4 & 4 & 4 & 4 & 4 & 4 & 4 \\
\hline 3 & 4 & 4 & 4 & 4 & 4 & 4 & 4 & 4 & 4 \\
\hline 4 & 4 & 4 & 4 & 4 & 4 & 4 & 4 & 2 & 4 \\
\hline 4 & 4 & 4 & 4 & 4 & 4 & 5 & 5 & 4 & 4 \\
\hline 4 & 4 & 4 & 4 & 4 & 4 & 4 & 4 & 3 & 4 \\
\hline 4 & 4 & 4 & 4 & 4 & 4 & 4 & 2 & 4 & 4 \\
\hline 4 & 4 & 4 & 4 & 4 & 4 & 4 & 4 & 4 & 4 \\
\hline 4 & 4 & 3 & 4 & 4 & 4 & 4 & 4 & 4 & 4 \\
\hline 4 & 4 & 4 & 4 & 4 & 4 & 4 & 4 & 4 & 4 \\
\hline 4 & 4 & 4 & 4 & 4 & 4 & 4 & 4 & 4 & 4 \\
\hline 90 & 98 & 100 & 98 & 98 & 100 & 97 & 97 & 98 & 100 \\
\hline 125 & 125 & 125 & 125 & 125 & 125 & 125 & 125 & 125 & 125 \\
\hline 72 & 78.4 & 80 & 78.4 & 78.4 & 80 & 77.6 & 77.6 & 78.4 & 80 \\
\hline
\end{tabular}

Dari hasil analisis pada Tabel 4.2, nilai terendah sebesar 72 untuk poin kepuasan mahasiswa terhadap dosen dan tenaga kependidikan di dalam melayani para mahasiswa. Tabel 4.3 di bawah ini berisi data hasil penilaian responden untuk mengevaluasi hasil pertumbuhan dan pembelajaran kepada para pengguna. 
Tabel 4.3. Skor Jawaban Responden tentang Pertumbuhan dan Pembelajaran

\begin{tabular}{|c|c|c|c|c|c|c|c|c|c|}
\hline \multicolumn{7}{|c|}{ Item Kuisioner } \\
\hline 1 & 2 & 3 & 4 & 5 & 6 & 7 & 8 & 9 & 10 \\
\hline 4 & 4 & 4 & 4 & 4 & 4 & 4 & 4 & 4 & 2 \\
\hline 4 & 5 & 3 & 4 & 4 & 4 & 4 & 4 & 4 & 4 \\
\hline 3 & 3 & 4 & 4 & 2 & 4 & 4 & 4 & 4 & 3 \\
\hline 4 & 4 & 4 & 4 & 3 & 4 & 4 & 4 & 4 & 4 \\
\hline 4 & 4 & 4 & 4 & 2 & 2 & 4 & 4 & 4 & 4 \\
\hline 2 & 4 & 4 & 4 & 2 & 4 & 4 & 5 & 4 & 4 \\
\hline 3 & 4 & 4 & 4 & 3 & 3 & 4 & 4 & 4 & 4 \\
\hline 3 & 4 & 4 & 4 & 5 & 4 & 4 & 3 & 4 & 4 \\
\hline 4 & 4 & 4 & 2 & 4 & 4 & 4 & 2 & 3 & 4 \\
\hline 2 & 4 & 4 & 4 & 5 & 3 & 4 & 4 & 4 & 4 \\
\hline 4 & 2 & 4 & 4 & 4 & 2 & 4 & 4 & 3 & 4 \\
\hline 4 & 3 & 3 & 3 & 3 & 4 & 4 & 4 & 4 & 4 \\
\hline 3 & 3 & 2 & 4 & 4 & 3 & 2 & 4 & 4 & 4 \\
\hline 4 & 4 & 4 & 4 & 5 & 4 & 5 & 4 & 4 & 4 \\
\hline 2 & 4 & 4 & 4 & 5 & 2 & 4 & 4 & 4 & 3 \\
\hline 3 & 4 & 4 & 4 & 5 & 4 & 4 & 4 & 4 & 4 \\
\hline 2 & 4 & 3 & 4 & 2 & 3 & 4 & 4 & 4 & 4 \\
\hline 4 & 4 & 4 & 4 & 3 & 5 & 4 & 5 & 4 & 4 \\
\hline 4 & 4 & 4 & 4 & 5 & 4 & 4 & 4 & 4 & 5 \\
\hline 4 & 2 & 4 & 5 & 4 & 4 & 4 & 4 & 5 & 4 \\
\hline 4 & 4 & 4 & 2 & 4 & 4 & 4 & 4 & 4 & 4 \\
\hline 3 & 4 & 4 & 4 & 3 & 4 & 4 & 4 & 4 & 5 \\
\hline 4 & 5 & 4 & 4 & 2 & 4 & 4 & 4 & 4 & 4 \\
\hline 3 & 4 & 3 & 4 & 2 & 4 & 4 & 4 & 4 & 4 \\
\hline 5 & 4 & 5 & 4 & 4 & 4 & 4 & 4 & 4 & 4 \\
\hline 86 & 95 & 95 & 96 & 89 & 91 & 99 & 99 & 99 & 98 \\
\hline 125 & 125 & 125 & 125 & 125 & 125 & 125 & 125 & 125 & 125 \\
\hline $\mathbf{6 8 . 8}$ & 76 & 76 & 76.8 & 71.2 & 72.8 & 79.2 & 79.2 & 79.2 & 78.4 \\
\hline & & & & & & 4 \\
\hline 4
\end{tabular}

\section{Kesimpulan Dan Saran}

\subsection{Kesimpulan}

STT CSK sebagai institusi pendidikan tinggi telah memahami, mengelola, mengembangkan dan menerapkan Knowledge Management System yang dimiliki dapat menciptakan keunggulan daya saing serta mewujudkan visi, misi dan tujuan institusi.

Konsep Balanced Scorecard dapat diadaptasi untuk digunakan oleh sebuah sistem website untuk memastikan bahwa investasi berupa sistem website tersebut selaras dengan strategi institusi.

\subsection{Saran}

Beberapa saran yang perlu disampaikan oleh peneliti adalah STT CSK disarankan untuk melakukan survei kepuasan terhadap pengguna dengan model BSC minimal sekali dalam setahun agar dapat mengevaluasi kinerja sistem website secara berkesinambungan dan berusaha untuk terus meningkatkan kualitas sumber daya manusia sehingga dapat memberikan pelayanan yang terbaik bagi para pengguna sistem website. 


\section{References}

[1] Yuliazmi. (2005). Penerapan Knowledge Management Pada Perusahaan Reasuransi, Studi Kasus: PT. Reasuransi Nasional Indonesia. http://riyogarta.com/downloads/tesis_yuliazmi.pdf.

[2] Davenport, Thomas, H and Laurence Prusak. (1998). Working Knowledge: How Organitations Manage What They Know. Harvard Business School Press, Boston.

[3] Bacerra-Fernandez, Irma, Avelino Gonzalez, and Rajiv Shaberwal. (2003). Knowledge management: Challanges, Solution and Technologies. New Jersey: Pearson Education.

[4] Budihardjo,Andreas. (2017). Knowledge Management. Prasetiya Mulya Publishing, Jakarta.

[5] http://www.cahayasurya.ac.id : Akses 4 Agustus 2019.

[6] Kaplan, Robert S. and Norton, David P. The Balanced Scorecard - Measures that Drive Performance. Harvard Business Review, vol. January-February, p. 71-79. 1992.

[7] Sari, Kurnia. W dan Tania, Ditha. K (2014). Penerapan Knowledge Management System (KMS) Berbasis Web Studi Kasus Bagian Teknisi dan Jaringan Fakultas Ilmu Komputer Universitas Sriwijaya. Jurnal Sistem Informasi (JSI), VOL. 6, NO. 2,Oktober 2014, ISSN Print : 2085-1588 ISSN Online 2355-4614, http://ejournal.unsri.ac.id/index.php/jsi/index.

[8] Tiwana, Amrit. (1999). The Knowledge management Toolkit. London: Prentice Hall.

[9] S. W. Mudjanarko, S. Winardi, and A. D. Limantara, "Pemanfaatan internet of things (IoT) sebagai solusi manejemen transportasi kendaraan sepeda motor," Pros. Semin. Nas. Apl. Teknol. Prasarana Wil. X, no. August, 2017.

[10] A. D. Triono et al., "Utilization of Pedestrian Movement on the Sidewalk as a Source of Electric Power for Lighting Using Piezoelectric Censors," in 2018 3rd IEEE International Conference on Intelligent Transportation Engineering, ICITE 2018, 2018.

[11] A. D. Limantara, L. D. Krisnawati, S. Winardi, and S. W. Mudjanarko, "Solusi Pengawasan Kebijakan Mengatasi Kemacetan Jalan dan Parkir Kota Berbasis Internet Cerdas," Semin. Nas. Teknol. dan Rekayasa Inf., no. November, pp. 1-6, 2017.

[12] A. D. Limantara, S. Winarto, and S. W. Mudjanarko, "Sistem Pakar Pemilihan Model Perbaikan Perkerasan Lentur berdasarkan Indeks Kondisi Perkerasan (Pci)," Semin. Nas. dan Teknol. Fak. Tek. Universtas Muhammadiyah Surakarta, no. November, pp. 1-2, 2017.

[13] A. D. Limantara, Y. Cahyo, S. Purnomo, and S. W. Mudjanarko, "Pemodelan Sistem Pelacakan LOT Parkir Kosong Berbasis Sensor Ultrasonic Dan Internet Of Things (IoT) Pada Lahan Parkir Diluar Jalan," Semin. Nas. Sains dan Teknol., vol. 1, no. 2, pp. 1-10, 2017.

[14] A. Alimudin, A. Z. Falani, S. W. Mudjanarko, and A. D. Limantara, "Analisis Pengaruh Penerapan Perspektif Balanced Scorecard Terhadap Peningkatan Kinerja UMKM," Ekonika J. Ekon. Univ. kadiri, vol. 4, no. 1, p. 1, 2019. 